Article

\title{
Studying the Degree of Tooth Enamel Mineralization through Raman Spectroscopy in Various Spectral Ranges
}

\author{
Diana V. Prikule ${ }^{1}\left(\right.$, Vladimir I. Kukushkin ${ }^{2, *} \mathbb{0}$, Aleksandr V. Mitronin ${ }^{1}$ and Vladislav F. Prikuls ${ }^{3}$ \\ 1 Department of Cariology and Endodontics, A.I. Evdokimov Moscow State University of Medicine and \\ Dentistry of the Ministry of Healthcare of the Russian Federation, 127473 Moscow, Russia; \\ brizitta@mail.ru (D.V.P.); mitroninav@list.ru (A.V.M.) \\ 2 Laboratory of Non-Equilibrium Electronic Processes, Institute of Solid State Physics of Russian Academy of \\ Sciences, 142432 Chernogolovka, Russia \\ 3 The National Medical Research Center for Otorhinolaryngology of the Federal Medico-Biological Agency of \\ Russia, 123182 Moscow, Russia; vlad_doc@list.ru \\ * Correspondence: kukushvi@mail.ru; Tel.: +7-905-502-92-77
}

Citation: Prikule, D.V.; Kukushkin, V.I.; Mitronin, A.V.; Prikuls, V.F. Studying the Degree of Tooth Enamel Mineralization through Raman Spectroscopy in Various Spectral Ranges. Biophysica 2021, 1, 269-278. https://doi.org/10.3390/ biophysica1030020

Academic Editor: Victor Muñoz

Received: 14 April 2021

Accepted: 20 June 2021

Published: 28 June 2021

Publisher's Note: MDPI stays neutral with regard to jurisdictional claims in published maps and institutional affiliations.

Copyright: (c) 2021 by the authors. Licensee MDPI, Basel, Switzerland. This article is an open access article distributed under the terms and conditions of the Creative Commons Attribution (CC BY) license (https:/ / creativecommons.org/licenses/by/ $4.0 /)$.

\begin{abstract}
In vitro and in vivo methods of Raman spectroscopy have been developed to assess the degree of mineralization of the enamel of different functional groups. This article presents comparative studies that were carried out using scanning Raman microspectroscopy with various sources of laser excitation with wavelengths of 532, 785, and $1064 \mathrm{~nm}$. It is shown that the intensity of Raman scattering of enamel can be a measure of its thickness. The obtained dependence of the Raman scattering intensity on the distance from the incisal edge is in good agreement with the literature data, where two independent methods (computer tomography and electron microscopy) are used to determine the enamel thickness values. The proposed methods can be considered as potential quantitative methods for express diagnostics of the state of tooth enamel in vivo.
\end{abstract}

Keywords: Raman spectroscopy; diagnosis; hydroxyapatite; tooth enamel; demineralization

\section{Introduction}

According to Global Disease Severity Survey 2016, at least 3.58 billion people suffered from oral diseases worldwide that year, and the most prevalent health disorder was dental caries in permanent teeth [1]. The problem of diagnostics and prevention of caries development is socially significant. Various instrumental and hardware diagnostic methods are used to solve this problem. The methods of digital diagnostics applied in hardware research are more informative. One of the most common and easily accessible methods is to conduct X-ray examinations: intraoral, extraoral, and plain radiography. However, it is necessary to consider the disadvantages of this technique: the negative effect of ionizing radiation, the impossibility to identify the initial stages of the carious process, and enamel demineralization [2]. There is another popular method that is the electric pulp test, which is used to determine the threshold of pulp sensitivity to electrical current. At the same time, the disadvantage of this method is its inability to determine the depth and the activity of the pathological process [3]. The next method is laser fluorescence diagnostics developed by KaVo (DIAGNOdent, Germany) used to identify the presence of the structural changes in the dental hard tissues of the teeth exposed to radiation with a wavelength of $655 \mathrm{~nm}$ and a threshold power of $1 \mathrm{mV}$. Unfortunately, DIAGNOdent does not allow us to run diagnostics on the approximal surfaces of the teeth that make it less frequently used [4]. There is also a method of quantitative light fluorescence based on fluorescence diagnostics. The device possesses a blue spectrum of radiation with a wavelength of $370 \mathrm{~nm}$ transmitted through a liquid-filled guide. This method is based on the fluorescence imaging of affected and intact tooth hard tissues. Nevertheless, this technique does not digitalize the level of destruction in the numeric values needed for the statistical analysis with dynamic observation [5]. The 
method for measuring the thickness of the enamel with ultrasonic waves based on the result of acoustic measurements is used to distinguish the difference between the intact and affected enamel. At the same time, it is difficult to carry out research using this method, and it does not determine the initial manifestation of the process [6].

The most innovative and promising method for diagnosing enamel demineralization and developing a carious process is optical spectroscopy. It is known that the development of subsurface demineralization of tooth enamel is a key factor for early diagnosis of the onset of the carious process [7]. The structural unit of tooth enamel is an enamel prism, the main component of which is represented by the crystalline compound hydroxyapatite $\left(\mathrm{Ca}_{10}\left(\mathrm{PO}_{4}\right)_{6}(\mathrm{OH})_{2}\right)$. Vibrational spectroscopy methods (IR spectroscopy and Raman spectroscopy) are the main methods for studying the structural features and defects of crystalline mineral compounds [8], such as tooth enamel [9] and bone tissues [10]. The Raman scattering spectra of crystals exhibit high-intensity narrow-spectral phonon modes of crystal lattice oscillations, which makes it possible to study it in detail.

Raman diagnostic methods are widely used in medicine to detect various pathological processes in the body, including malignant neoplasms [11-13]. Laser Raman diagnostics is used in microbiology [14], medicine [15-17], and many other fields [18-20]. The spectral analysis makes it possible to determine the "fingerprint" of each molecule under investigation. Preliminary preparatory work is not required for express diagnostics, due to the possible individualization of the study in each individual case.

The method of Raman spectroscopy creates an informative database of reference values of the spectral parameters of enamel [9]. Several researchers are currently developing an algorithm for this study, mainly in vitro [9,21-23].

Tomasz Buchwald and Zuzanna Buchwald [22] evaluated how effective Raman spectroscopy was in determining specific changes caused by caries in the tooth enamel composition. The results of the spectroscopy of the enamel with "natural" and "artificially induced" caries were obtained, and a comparative assessment of them was made. Seven permanent molars extracted for indications were selected for the study. The molars had neither visible enamel defects nor carious lesions. The teeth were cleaned with a soft toothbrush and placed in distilled water. Then they were kept in a demineralizing solution. Thus, the authors made it possible to divide the enamel surface into demineralized and non-demineralized areas. The Renishaw inVia confocal Raman microscope with a wavelength of $514.5 \mathrm{~nm}$ and $785 \mathrm{~nm}$ was used for the study. The results proved a possible use of this spectroscopy to determine accurately the enamel demineralization even at the early stages that are not visible to the eye.

Mandra J.V. et al. [23] studied the structural characteristics of the dental hard tissues in carious and non-carious lesions, determined the spectrum of the samples through Raman radiation, and evaluated the crystallinity and the orderliness of the hydroxyapatite structure. Sixteen teeth extracted for indications were taken for the study: Four intact ones, four carious ones, four pulpless ones, and four teeth with high abrasion. The teeth were washed in running water, purified from the soft tissue residues, treated with antiseptics, and maintained in $0.9 \%$ sodium chloride solution at a temperature of $5-7{ }^{\circ} \mathrm{C}$. Two samples of the hard tissues of enamel and dentin (size $2 \mathrm{~mm} \times 2 \mathrm{~mm} \times 1 \mathrm{~mm}$ ) were made from each tooth. The experiment was carried out on the LabRam HR Raman spectrometer (HORIBA Scientific) with a wavelength of $632 \mathrm{~nm}$. The results proved that the IR-Raman spectroscopy is informative to study the structural characteristics of the mineral components of dental hard tissues.

In our research, it was shown that the use of Raman spectroscopy allows real-time in vivo determination of the degree of mineralization of tooth enamel and its thickness.

\section{Materials and Methods}

\subsection{Raman Spectroscopy}

Primary studies were performed on the removed teeth using scanning Raman microspectroscopy on an Olympus BX51 (Olympus Corporation, Tokyo, Japan) microscope based on Raman spectrometers with wavelengths of 532, 785, and $1064 \mathrm{~nm}$. 
The spectrometer EnSpectr R532 (Enhanced Spectrometry, Inc., San Jose, CA, USA) with a wavelength of $532 \mathrm{~nm}$ had a spectral resolution of $4-6 \mathrm{~cm}^{-1}$ and a spectral range of 180-4000 $\mathrm{cm}^{-1}$. The spectrometer EnSpectr R785 (Enhanced Spectrometry, Inc., San Jose, CA, USA) with a wavelength of $785 \mathrm{~nm}$ had a spectral resolution of $6-8 \mathrm{~cm}^{-1}$ and a spectral range of 150-2700 $\mathrm{cm}^{-1}$. The spectrometer IR Raman Analyzer R1064 (Enhanced Spectrometry, Inc., San Jose, CA, USA) with a wavelength of $1064 \mathrm{~nm}$ had a spectral resolution of 7-9 $\mathrm{cm}^{-1}$ and a spectral range of $200-1850 \mathrm{~cm}^{-1}$. For the spectrometer EnSpectr R532the laser power was $25 \mathrm{~mW}$, for the EnSpectr R785-180 mW, and for the EnSpectr R1064-250 mW. The beam diameter for each of the above-mentioned spectrometers was $3 \mathrm{mkm}$.

A motorized XY scanning stage 8MTF (Standa Ltd., Vilnius, Lithuania) with a travel range of $75 \times 75 \mathrm{~mm}$ was used for Raman mapping and scanning.

In our research of demineralization degree in various teeth functional groups in vivo, we use the hardware and software PHOTON-BIO 532 (PHOTON-BIO, Inc., Domodedovo, Russia) complex. It is a fiber device to diagnose caries on intact teeth even in hard-to-reach places with a digital response in online mode. This fiber Raman spectrometer with a laser radiation wavelength of $532 \mathrm{~nm}$, a spectral resolution of $8 \mathrm{~cm}^{-1}$, and a spectral range of 200-4000 $\mathrm{cm}^{-1}$ has a medical registration certificate № RZN 2020/10719 dated 11 June 2020. The laser radiation power was $20 \mathrm{~mW}$, the diameter of the exciting fiber was $200 \mathrm{mkm}$, and the angular aperture was $0.22 \mathrm{rad}$.

The fiber instrument had two cores with a diameter of 200 microns each (one channel for laser excitation, and the second for signal collection).

To ensure a sterile contact between the fiber instrument and the patient, a protective sterile optical cap PHOTON-BIO D (PHOTON-BIO, Inc., Domodedovo, Russia) was placed on the fiber instrument. The optical cap has a medical registration certificate № RZN 2021/13513 dated 20 February 2021.

\subsection{Samples of Removed Teeth}

The extracted teeth were cleaned of soft tissue and placed in distilled water in a closed container. The study was carried out within 1-2 days after the removal.

To reduce the measurement error, the extracted teeth were placed in a plaster retainer, and each was assigned an ordinal number.

For the convenience of assessing the mineralization of anatomical and topographic zones, each tooth was divided into three sectors: The cutting edge (junction of vestibular and occlusal surfaces), the equator, and the cervical region.

\subsection{Patient Groups}

At the clinical stage of the study, Raman diagnostics of enamel in the area of the vestibular surface of the upper jaw teeth (incisors, canines, premolars, and molars) was performed in vivo in 32 patients aged 20 to 25 years in an equal gender ratio.

The following inclusion criteria were applied: Men and women from 20 to 25 years of age; non-inclusion criteria: The presence of filling material and prosthodontic structures, carious and non-carious lesions on the investigated surface, as well as decompensated chronic diseases and pregnancy.

The standard oral hygiene procedure was performed before the Raman spectroscopy in vivo.

\section{Results}

\subsection{Scanning Raman Microscopy}

At the first stage of the work on extracted molars, using scanning Raman microscopy with a wavelength of exciting laser radiation of $1064 \mathrm{~nm}$, the dependences of the change in the intensity of the main Raman peak of $960 \mathrm{~cm}^{-1}$ (the line of symmetric valence oscillation $\mathrm{PO}_{4}{ }^{3-}$ [23]) on the border between the cutting edge of the tooth and the cervical region were studied. The obtained dependence of the Raman scattering intensity on the distance from the incisal edge (Figure 1) is in good agreement with the literature data [24], where two 
independent methods (computer tomography (Table 1) and electron microscopy (Table 2)) were used to determine the enamel thickness values of different teeth in different areas (cutting edge, equator, cervical region) on a large sample of patients.

Table 1. Enamel thickness in the cervical region, equator, and the cutting edge. Multispiral computed tomography (MSCT) method [24].

\begin{tabular}{cccc}
\hline Tooth Type & Cervical Region, Thickness, mm & Equator, Thickness, mm & Cutting Edge, Thickness, mm \\
\hline \multicolumn{3}{c}{ Upper jaw } \\
\hline Incisor 1 & $0.27 \pm 0.01$ & $0.84 \pm 0.05$ & $0.97 \pm 0.06$ \\
\hline Incisor 2 & $0.32 \pm 0.01$ & $0.92 \pm 0.06$ & $1.04 \pm 0.06$ \\
\hline Canine & $0.28 \pm 0.01$ & $0.79 \pm 0.05$ & $0.89 \pm 0.05$ \\
\hline Premolar 1 & $0.31 \pm 0.01$ & $1.01 \pm 0.06$ & $1.33 \pm 0.08$ \\
\hline Premolar 2 & $0.36 \pm 0.02$ & $1.11 \pm 0.07$ & $1.56 \pm 0.09$ \\
\hline Molar 1 & $0.38 \pm 0.02$ & $1.25 \pm 0.08$ & $1.76 \pm 0.11$ \\
\hline Molar 2 & $0.39 \pm 0.02$ & $1.31 \pm 0.08$ & $1.89 \pm 0.11$ \\
\hline Incisor 1 & & \\
\hline Incisor 2 & $0.17 \pm 0.01$ & $0.73 \pm 0.04$ & $0.89 \pm 0.05$ \\
\hline Canine & $0.23 \pm 0.01$ & $0.83 \pm 0.05$ & $0.98 \pm 0.06$ \\
\hline Premolar 1 & $0.19 \pm 0.01$ & $0.78 \pm 0.05$ & $0.84 \pm 0.05$ \\
\hline Premolar 2 & $0.21 \pm 0.01$ & $0.98 \pm 0.06$ & $1.41 \pm 0.08$ \\
\hline Molar 1 & $0.23 \pm 0.01$ & $1.02 \pm 0.06$ & $1.58 \pm 0.09$ \\
\hline Molar 2 & $0.24 \pm 0.01$ & $1.17 \pm 0.07$ & $1.68 \pm 0.10$ \\
\hline & $0.30 \pm 0.02$ & $1.21 \pm 0.07$ & $1.72 \pm 0.10$ \\
\hline
\end{tabular}

Table 2. Enamel thickness in the cervical region, equator, and the cutting edge. Scanning electron microscopy (SEM) method [24].

\begin{tabular}{cccc}
\hline Tooth Type & Cervical Region, Thickness, mm & Equator, Thickness, mm & Cutting Edge, Thickness, mm \\
\hline Incisor 1 & Upper jaw & $0.90 \pm 0.05$ \\
\hline Incisor 2 & $0.19 \pm 0.02$ & $0.73 \pm 0.04$ & $0.97 \pm 0.06$ \\
\hline Canine & $0.23 \pm 0.02$ & $0.89 \pm 0.05$ & $0.80 \pm 0.05$ \\
\hline Premolar 1 & $0.20 \pm 0.02$ & $0.76 \pm 0.05$ & $1.20 \pm 0.07$ \\
\hline Premolar 2 & $0.22 \pm 0.02$ & $0.98 \pm 0.06$ & $1.30 \pm 0.08$ \\
\hline Molar 1 & $0.27 \pm 0.03$ & $1.05 \pm 0.06$ & $1.88 \pm 0.11$ \\
\hline Molar 2 & $0.30 \pm 0.03$ & $1.20 \pm 0.07$ & $1.93 \pm 0.12$ \\
\hline Incisor 1 & $0.34 \pm 0.03$ & $1.27 \pm 0.08$ & $0.80 \pm 0.05$ \\
\hline Incisor 2 & & Lower jaw & $0.91 \pm 0.05$ \\
\hline Canine & $0.15 \pm 0.02$ & $0.67 \pm 0.04$ & $0.78 \pm 0.05$ \\
\hline Premolar 1 & $0.20 \pm 0.02$ & $0.80 \pm 0.05$ & $1.20 \pm 0.07$ \\
\hline Premolar 2 & $0.17 \pm 0.02$ & $0.70 \pm 0.04$ & $1.20 \pm 0.07$ \\
\hline Molar 1 & $0.19 \pm 0.02$ & $0.92 \pm 0.06$ & $1.70 \pm 0.10$ \\
\hline Molar 2 & $0.21 \pm 0.02$ & $0.97 \pm 0.06$ & $1.77 \pm 0.11$ \\
\hline
\end{tabular}




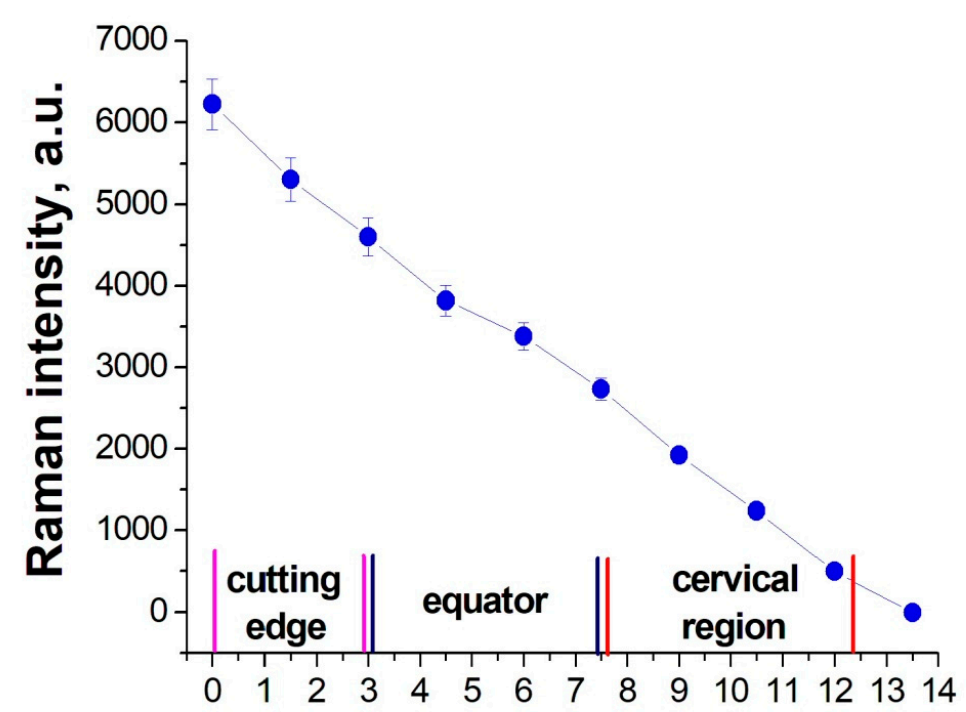

Distance from the cutting edge, $\mathrm{mm}$

Figure 1. Graph of the Raman scattering intensity dependence on the spatial point on the surface of the molar enamel This dependence was obtained by averaging 50 Raman line scans (on 1 molar) with a scan step of $1.5 \mathrm{~mm}$. The laser excitation wavelength is $1064 \mathrm{~nm}$, the exposure time is $4 \mathrm{~s}$, and the number of frames for recording a single spectrum is 10 .

In Figure 1, the Y-axis shows the Raman scattering intensity averaged over 50 measurements at various points of the molar enamel, minus the background intensity of the Raman scattering of the tooth dentin. This curve can be used for further quantitative analysis of the enamel thickness. In total, 10 molars were involved in the study, and all of them had a similar type of linear-decreasing dependence.

\subsection{Choosing the Optimal Raman System}

As a result of comparing the data obtained on spectrometers with different wavelengths of laser emitters (Figure 2), it was found that the use of an exciting laser wavelength of $532 \mathrm{~nm}$ (despite the photoluminescence signal) is optimal, due to the highest sensitivity of the optical response detection (the peak intensity of $960 \mathrm{~cm}^{-1}$ was 14 thousand counts per second for a spectrometer with a wavelength of $532 \mathrm{~nm}, 2$ thousand counts per second for a spectrometer with a wavelength of $785 \mathrm{~nm}, 2$ thousand counts per second for a spectrometer with a wavelength of $1064 \mathrm{~nm}$ ).

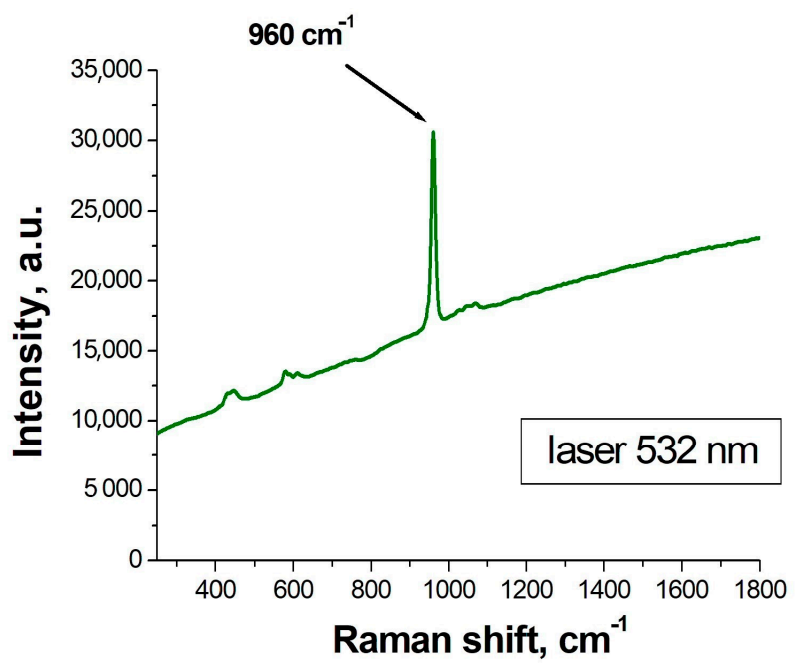

A

Figure 2. Cont. 


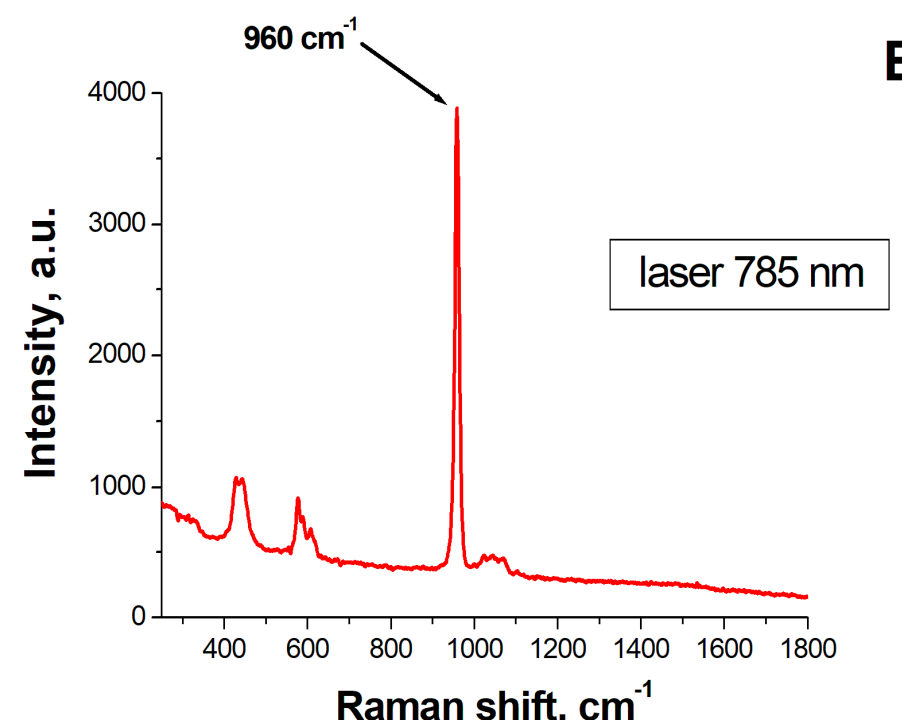

B

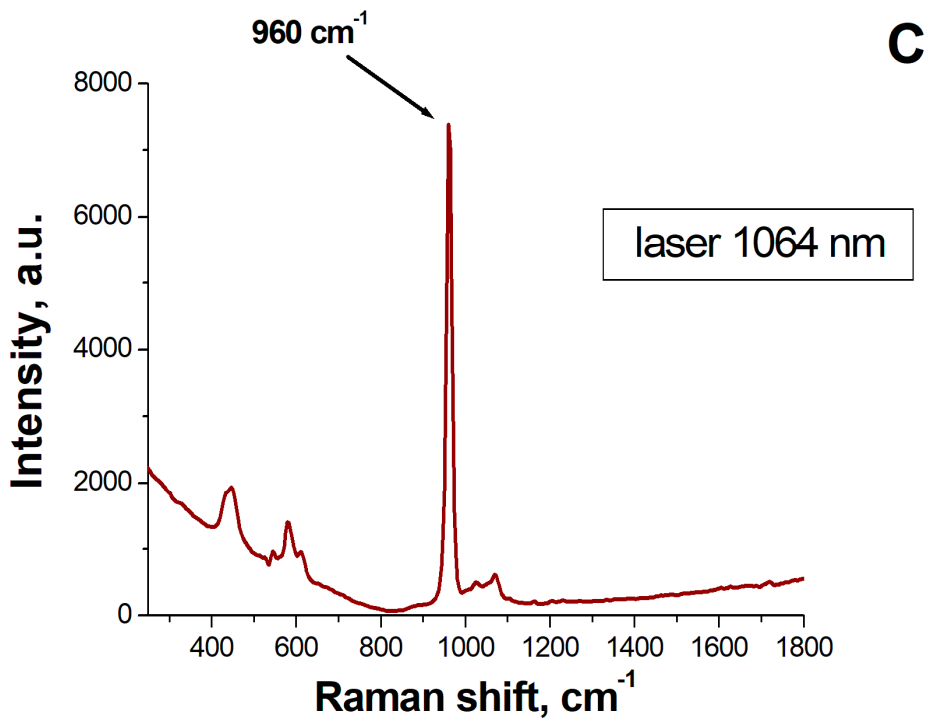

Figure 2. Raman scattering spectra of tooth enamel when excited by laser sources with wavelengths: (A)-532 nm (exposure time-1 s), (B)-785 nm (exposure time-2 s), (C)-1064 nm (exposure time-4 s).

\subsection{Raman Fiber Spectroscopy In Vitro}

During the Raman fiber spectroscopy with a laser radiation wavelength of $532 \mathrm{~nm}$ on the removed teeth, the average values and standard deviation of the intensity of the hydroxyapatite line of $960 \mathrm{~cm}^{-1}$ were obtained for various groups of teeth and their measurement areas. A total of 10 incisors, 10 canines, 10 molars, and 10 premolars were examined (Table 3). The exposure time for recording the spectra was $2 \mathrm{~s}$ with 20 averaging. The power of the laser radiation was $25 \mathrm{~mW}$. 
Table 3. The intensity of Raman scattering on different removed teeth, depending on the measurement point.

\begin{tabular}{|c|c|}
\hline Research Area & Intensity of Raman Scattering, a.u. \\
\hline \multicolumn{2}{|c|}{ Incisors ( $\mathrm{N}=10)$} \\
\hline Cervical region & $807 \pm 24$ \\
\hline Equator & $927 \pm 19$ \\
\hline Cutting edge & $879 \pm 21$ \\
\hline \multicolumn{2}{|c|}{ Canines $(\mathrm{N}=10)$} \\
\hline Cervical region & $738 \pm 22$ \\
\hline Equator & $1102 \pm 24$ \\
\hline Cutting edge & $1312 \pm 28$ \\
\hline \multicolumn{2}{|c|}{ Premolars $(\mathrm{N}=10)$} \\
\hline Cervical region & $713 \pm 25$ \\
\hline Equator & $1021 \pm 23$ \\
\hline Cutting edge & $1117 \pm 26$ \\
\hline \multicolumn{2}{|c|}{ Molars (N = 10) } \\
\hline Cervical region & $679 \pm 20$ \\
\hline Equator & $931 \pm 29$ \\
\hline Cutting edge & $993 \pm 31$ \\
\hline
\end{tabular}

\subsection{Raman Fiber Spectroscopy In Vivo}

At the second stage of the research, a fiber Raman spectrometer with a laser radiation wavelength of $532 \mathrm{~nm}$ was used on patients. The results of the studies conducted at the clinical stage of the study (64 incisors, 64 canines, 64 molars, and 64 premolars were examined) are consistent (Table 4) with the data obtained at the first experimental stage of work on removed teeth. The exposure time for recording the spectra was $2 \mathrm{~s}$ with 20 averaging. The power of the laser radiation was $25 \mathrm{~mW}$.

Table 4. The intensity of Raman scattering on different teeth of patients depending on the measurement point.

\begin{tabular}{|c|c|}
\hline Research Area & Intensity of Raman Scattering, a.u. \\
\hline \multicolumn{2}{|c|}{ Incisors $(\mathrm{N}=64)$} \\
\hline Cervical region & $153 \pm 27$ \\
\hline Equator & $157 \pm 23$ \\
\hline Cutting edge & $140 \pm 22$ \\
\hline \multicolumn{2}{|c|}{ Canines $(\mathrm{N}=64)$} \\
\hline Cervical region & $145 \pm 24$ \\
\hline Equator & $157 \pm 28$ \\
\hline Cutting edge & $167 \pm 29$ \\
\hline \multicolumn{2}{|c|}{ Premolars $(\mathrm{N}=64)$} \\
\hline Cervical region & $140 \pm 11$ \\
\hline Equator & $150 \pm 14$ \\
\hline Cutting edge & $165 \pm 15$ \\
\hline \multicolumn{2}{|c|}{ Molars $(\mathrm{N}=64)$} \\
\hline Cervical region & $147 \pm 32$ \\
\hline Equator & $160 \pm 21$ \\
\hline Cutting edge & $178 \pm 22$ \\
\hline
\end{tabular}


The difference in the optical response from the surface of the teeth in vivo (Table 4) and in vitro (Table 3) under the same conditions of signal registration is probably because, despite the standard oral hygiene procedure carried out by patients, microbial plaque remains on the surface of the teeth [25], which effectively absorbs and scatters visible highfrequency laser radiation. In addition, it is also necessary to consider that the presence of fluid circulation in the dentine tubules of vital teeth may cause differences in the obtained indicators during Raman diagnostics on vital and removed teeth.

The dependences of the intensity of the $960 \mathrm{~cm}^{-1}$ hydroxyapatite peak on the area on the surface of the teeth have the same appearance when conducting experiments under different conditions (at different wavelengths of exciting radiation on a Raman microscope, using in vitro and in vivo fiber spectrometers).

\section{Conclusions}

The studies conducted in the experimental stage of work on the removed teeth are consistent with the data obtained at the clinical stage of the study. It is established that the maximum intensity of Raman scattering corresponds to the region of the equator at the incisors, and to the cutting edge region of the canines, premolars, and molars. Thus, we have observed correlations between changes in the enamel thickness (according to [24]) and the intensity of Raman scattering. The intensity of Raman scattering of enamel can be considered a measure of its thickness, and therefore, the use of Raman spectrometry determines the degree of mineralization of tooth enamel in real-time.

It should be noted that in contrast to the surface probing by laser radiation of the visible range of the body soft tissues (the penetration depth of laser radiation with a wavelength of $532 \mathrm{~nm}$ in the tissues is about $500 \mathrm{mkm}$ [26]), in the case of interaction of laser radiation with hard tissues of the teeth, the penetration depth is about $1 \mathrm{~cm}$ for a wavelength of $780 \mathrm{~nm}$ [27], and has approximately the same value for laser radiation with a wavelength of $532 \mathrm{~nm}$ [28].

Hence, in our opinion, this method of express-diagnostics is promising for the differential diagnosis of teeth predisposition to caries. The implementation of the developed research method will increase the effectiveness of not only the diagnosis, but also the prevention of the dental hard tissues diseases development. It is established that the Raman scattering provides an opportunity to determine not only the static value of the dental tissues mineralization degree, but also to study the effect of remineralization in dynamics. Currently, there is no cheap and accurate method within global clinical practice for determining the thickness, degree of mineralization, and degree of crystallinity of tooth enamel in vivo. The degree of crystallinity/amorphousness can be determined by the half-width of the Raman lines of hydroxyapatite [29], which will be done in our subsequent works.

Therefore, this study is extremely promising and contributes to developing high-tech production of adapted software and hardware Raman spectrometers for diagnosing the condition of tooth enamel.

In addition, the authors of this study are working on the creation of an instrument in which there are three optical modules in one spectrometer (the Raman scattering module with a laser wavelength of $532 \mathrm{~nm}$, the photoluminescence module with a laser wavelength of $405 \mathrm{~nm}$, and the white light reflection module). Each type of optical signal has a diagnostic value for the diagnosis of the oral cavity. For example, the high-intensity photoluminescence of porphyrins when the oral mucosa is excited by laser radiation with a wavelength of $405 \mathrm{~nm}$ is an indicator of its high bacterial contamination, and the presence of inflammatory and precancerous processes [30]. The white light reflection spectrum is informative in detecting hypoxia [31] in the gum tissues, which can be useful for diagnosing developing periodontitis. The ensemble of these three methods, incorporated in a single device, is a promising tool for multifactorial diagnosis of the state of the oral cavity.

Author Contributions: Conceptualization, V.I.K. and A.V.M.; methodology, D.V.P. and V.I.K.; formal analysis, V.F.P.; writing - original draft preparation, D.V.P. and V.I.K.; writing-review and editing, D.V.P., V.I.K. and V.F.P. All authors have read and agreed to the published version of the manuscript. 
Funding: This research received no external funding.

Institutional Review Board Statement: There was no appeal to the Ethics Committee, because in this study we didn't carry out research conducted in humans. The standard diagnostics procedure was performed.

Informed Consent Statement: Informed consent was obtained from all subjects involved in the study.

Data Availability Statement: The data presented in this study are available on request from the corresponding author. The data are not publicly available due to privacy.

Acknowledgments: The authors are grateful to the Institute of Solid State Physics of the Russian Academy of Sciences (ISSP RAS).

Conflicts of Interest: The authors declare no conflict of interest.

\section{References}

1. GBD 2016 Disease and Injury Incidence and Prevalence Collaborators. Global, regional, and national incidence, prevalence, and years lived with disability for 328 diseases and injuries for 195 countries, 1990-2016: A systematic analysis for the Global Burden of Disease Study 2016. Lancet 2017, 390, 1211-1259. [CrossRef]

2. Gomez, J. Detection and diagnosis of the early caries lesion. BMC Oral Health 2015, 15 (Suppl. 1), S3. [CrossRef]

3. Kozhevnikova, A.I.; Klyagina, A.A. Electric pulp test in in the daily practice of a dentist. Bull. Med. Internet Conf. $2016,6,5$.

4. Nokhbatolfoghahaie, H.; Alikhasi, M.; Chiniforush, N.; Khoei, F.; Safavi, N.; Yaghoub Zadeh, B. Evaluation of Accuracy of DIAGNOdent in Diagnosis of Primary and Secondary Caries in Comparison to Conventional Methods. J. Lasers Med. Sci. 2013, 4, 159-167.

5. Granko, S.A.; Danilova, D.V.; Beloded, L.V. Diagnosis of initial carious lesions of hard tooth tissues. Sovremennayastomatologiya 2017, 4, 59-62.

6. Rusanov, F.S.; Maev, R.G.; Titov, S.A. Non-destructive method for measuring enamel thickness using ultrasonic waves. Stomatologiia 2012, 91, 4-6.

7. Yanushevich, O.O. Therapeutic Dentistry; Yanushevich, O.O., Maksimovskii, Y.M., Maksimovskaya, L.N., Orekhova, L.Y., Eds.; GEOTAR-Media: Moscow, Russia, 2016; 760p.

8. Chukanov, N.V. Raman Spectra of Minerals; Chukanov, N.V., Vigasina, M.F., Eds.; Springer Mineralogy; Springer: Cham, Switzerland, 2020; pp. 741-1255.

9. Ramakrishnaiah, R.; Rehman, G.; Basavarajappa, S. Applications of Raman Spectroscopy in Dentistry: Analysis of Tooth Structure. Appl. Spectrosc. Rev. 2015, 50, 332-350. [CrossRef]

10. Khalid, M.; Bora, T.; Ghaithi, A.A.; Thukral, S.; Dutta, J. Raman Spectroscopy detects changes in Bone Mineral Quality and Collagen Cross-linkage in Staphylococcus Infected Human Bone. Sci. Rep. 2018, 8, 9417. [CrossRef] [PubMed]

11. Kourkoumelis, N.; Balatsoukas, I.; Moulia, V.; Elka, A.; Gaitanis, G.; Bassukas, I.D. Advances in the in Vivo Raman Spectroscopy of Malignant Skin Tumors Using Portable Instrumentation. Int. J. Mol. Sci. 2015, 16, 14554-14570. [CrossRef]

12. Rau, J.V.; Graziani, V.; Fosca, M.; Taffon, C.; Rocchia, M.; Crucitti, P.; Pozzilli, P.; Onetti Muda, A.; Caricato, M.; Crescenzi, A. RAMAN spectroscopy imaging improves the diagnosis of papillary thyroid carcinoma. Sci. Rep. 2016, 6, 35117. [CrossRef]

13. Lorincz, A.; Haddad, D.; Naik, R.; Naik, V.M.; Fung, A.; Cao, A.; Manda, P.; Pandya, A.; Auner, G.; Rabah, R.; et al. Raman spectroscopy for neoplastic tissue differentiation: A pilot study. J. Pediatr. Surg. 2004, 39, 953-956. [CrossRef]

14. Wang, J.; Wu, X.; Wang, C.; Rong, Z.; Ding, H.; Li, H.; Li, S.; Shao, N.; Dong, P.; Xiao, R.; et al. Facile Synthesis of Au-Coated Magnetic Nanoparticles and Their Application in Bacteria Detection via a SERS Method. ACS Appl. Mater. Interfaces 2016, 8 , 19958-19967. [CrossRef]

15. Moncada, B.; Castillo-Martínez, C.; Arenas, E.; León-Bejarano, F.; Ramírez-Elías, M.G.; Gonzalez, F.J. Raman spectroscopy analysis of the skin of patients with melasma before standard treatment with topical corticosteroids, retinoic acid, and hydroquinone mixture. Skin Res. Technol. 2016, 22, 170-173. [CrossRef]

16. Hanchanale, V.S.; Rao, A.R.; Das, S. Raman spectroscopy and its urological applications. Indian J. Urol. 2008, 24, 444-450. [CrossRef]

17. Cui, X.; Zhao, Z.; Zhang, G.; Chen, S.; Zhao, Y.; Lu, J. Analysis and classification of kidney stones based on Raman spectroscopy. Biomed. Opt. Express 2018, 9, 4175-4183. [CrossRef]

18. John, M.C.; Howell, G.; Edwards, H.G.; Hargreaves, M.D. Infrared and Raman Spectroscopy in Forensic Science; Wiley: New York, NY, USA, 2012; 646p.

19. Vankeirsbilck, T.; Vercauteren, A.; Baeyens, W.; Van der Weken, G.; Verpoort, F.; Vergote, G.; Remon, J. Applications of Raman spectroscopy in pharmaceutical analysis. TrAC Trends Anal. Chem. 2002, 21, 869-877. [CrossRef]

20. Kudelski, A. Analytical applications of Raman spectroscopy. Talanta 2008, 76, 1-8. [CrossRef]

21. Votyakov, S.L.; Mandra, Y.V.; Kiseleva, D.V. Mineralogic al stomatology as an interdisciplinary research field: Recent results and development prospects. Probl. Dent. 2017, 13, 3-16. 
22. Buchwald, T.; Buchwald, Z. Assessment of the Raman spectroscopy effectiveness in determining the early changes in human enamel caused by artificial caries. Analyst. 2019, 144, 1409-1419. [CrossRef] [PubMed]

23. Mandra, Y.V.; Votyakov, S.L.; Ivashov, A.S.; Kiseleva, D.V. Possibilities of using Raman microscopy for studying structural features of hard tissues of human teeth. J. Exp. Clin. Dent. 2011, 1, 24-28.

24. Yanushevich, O.O. Photoluminescence of Dental Hard Tissues; Academia Estestvoznaniya: Moscow, Russia, 2014; 53p.

25. Prikuls, V.F.; Karneeva, O.V.; Kim, I.A.; Alexandrov, M.T.; Kukushkin, V.I.; Prikule, D.V. Oral hygiene level objectification in preventive screening of patients with ENT-organs pathology using digital optical diagnostics methods. Clin. Dent. 2020, 1, 34-39. [CrossRef]

26. Avci, P.; Gupta, A.; Sadasivam, M.; Vecchio, D.; Pam, Z.; Pam, N.; Hamblin, M. Low-Level Laser (Light) Therapy (LLLT) in skin: Stimulating, healing, restoring. Semin. Cutan. Med. Surg. 2013, 32, 41-52.

27. Polat, S.; Er, K.; Polat, N.T. Penetration depth of laser Doppler flowmetry beam in teeth. Oral Surg. Oral Med. Oral Pathol. Oral Radiol. Endod. 2005, 100, 125-129. [CrossRef] [PubMed]

28. Hoffmann, L.; Feraric, M.; Hoster, E.; Litzenburger, F.; Kunzelmann, K.-H. Investigations of the optical properties of enamel and dentin for early caries detection. Clin. Oral Investig. 2021, 25, 1281-1289. [CrossRef] [PubMed]

29. Schmid, T.; Dariz, P. Raman Microspectroscopic Imaging of Binder Remnants in Historical Mortars Reveals Processing Conditions. Heritage 2019, 2, 1662-1683. [CrossRef]

30. Kumar, P.; Kanaujia, S.K.; Singh, A.; Pradhan, A. In vivo detection of oral precancer using a fluorescence-based, in-housefabricated device: A Mahalanobis distance-based classification. Lasers Med. Sci. 2019, 34, 1243-1251. [CrossRef] [PubMed]

31. Bachir, W.; Hamadah, O. Second derivative diffuse reflectance spectroscopy for estimating tissue hypoxia. OSA Contin. 2021, 4, 650-664. [CrossRef] 